\title{
SYNCHRONIZATION OF STORAGE TANK VOLUME, DISPOSAL WELL VOLUME AND ELECTRIC SUBMERSIBLE PUMP (ESP) PUMP CAPACITY IN DISPOSAL WELL FIELD A (SINKRONISASI VOLUME TANGKI PENAMPUNGAN, VOLUME SUMUR DISPOSAL DAN KAPASITAS POMPA ESP PADA SUMUR DISPOSAL LAPANGAN A)
}

\author{
Ali Musnal ${ }^{1 *}$, Fitrianti $^{1}$ \\ ${ }^{1}$ Jurusan Teknik Perminyakan Fakultas Teknik Universitas Islam Riau \\ *corresponding author : ali.musnal@eng.uir.ac.id
}

\begin{abstract}
In the production of oil, a common problem faced by oil and gas companies is the over-production of water. Increased water production causes the storage tank to be incapable of accommodating the produced water. To overcome the excess water production, some of the water is injected back into the well. In Field A, an innovation has been achieved for regarding the water injection pump with the driving force coming from the Electrical Submersible Pump (ESP) pump. The working principle of this ESP pump is to drain water from the disposal well to the injection well. Therefore, in order for the injection to run optimally, synchronization is carried out starting from the water entering the holding tank, the flow rate in the Disposal well and the pump capacity (ESP) for injecting from the holding well to the injection well. The amount of water flow rate injected through the ESP pump is 9,500 BWPD. For this reason, the capacity of the ESP pump as an injection pump is calculated. Firstly, the water level in the tank is determined to control the amount of flow that enters the reservoir well. Based on the results of the research, the water level in the holding tank to attain a flow rate of 9,500 BWPD is $4.11 \mathrm{ft}$. And the results of the calculation of water will be injected using an ESP pump with 22 stages using the TRW Reda Pump Devision pump type. The water will be channeled to the injection well with a type of galvanized iron pipe with a main pipe (mainline) that is 6 inches in diameter. From the disposal well, it flows with a 4-inch pipe as far as $45.93 \mathrm{ft}$ and a 2-inch pipe as far as $2214.57 \mathrm{ft}$ for well 07. As for wells 60, the flowline size is 4 inches as far as $708.66 \mathrm{ft}$ and 2 inches as far as $987.53 \mathrm{ft}$.
\end{abstract}

Keywords: Disposal Well, electrical submersible pump, storage tank

\begin{abstract}
ABSTRAK
Dalam memproduksi minyak bumi, salah satu permasalahan umum yang dihadapi oleh perusahaan migas yaitu produksi air yang sangat banyak. Produksi air yang meningkat menyebabkan tangka penampungan tidak mampu menampung air yang diproduksi. Untuk menanggulangi kelebihan produksi air tersebut, sebagian air diinjeksikan kembali ke dalam sumur. Di Lapangan A, telah dilakukan inovasi untuk pompa injeksi air dengan tenaga pendorong berasal dari pompa Electrical Submersible Pump (ESP). Prinsip kerja dari pompa ESP ini yaitu dengan
\end{abstract}


mengalirkan air dari sumur penampungan (Sumur disposal) menuju sumur injeksi. Oleh karena itu, agar injeksi berjalan maksimal, dilakukan sinkronisasi mulai dari air masuk ke tangki penampungan, laju alir di sumur Disposal dan kapasitas pompa ESP untuk menginjeksikan dari sumur penampungan menuju sumur injeksi. Besarnya laju alir air yang diinjeksikan melalui pompa ESP sebesar 9.500 BWPD. Untuk itu dilakukan perhitungan kapasitas pompa ESP sebagai pompa injeksi. Terlebih dahulu ditentukan ketinggian air pada tangki untuk mengontrol besarnya laju alir yang masuk ke sumur penampungan. Berdasarkan hasil penelitian yang telah dilakukan, diperoleh ketinggian air pada tangki penampungan untuk mendapatkan laju alir 9.500 BWPD adalah 4,11 ft. Dan hasil perhitungan air akan diinjeksikan menggunakan pompa ESP dengan jumlah stage 22 dengan type pompa TRW Reda Pump DevisionReda I 300-60Hz-650 series- 3500 RPM. Air tersebut akan dialirkan menuju sumur injeksi dengan jenis pipa galvanized iron dengan diameter pipa utama (mainline) sebesar 6 inch. Dari sumur disposal dialirkan dengan pipa 4 inch sejauh 45,93ft dan pipa 2inch sejauh 2214,57 ft untuk sumur 07. Sedangkan untuk sumur 60 ukuran flowline 4 inch sejauh 708,66 ft dan ukuran 2 inch sejauh $987,53 \mathrm{ft}$.

Kata kunci : Electrical submersible pump, sumur disposal, tangki penampungan

\section{PENDAHULUAN}

Permasalahan umum yang dihadapi perusahaan migas pada saat ini dalam memproduksikan minyak bumi yaitu terproduksinya air yang sangat banyak. Hal ini disebabkan karena terjadinya penurunan tekanan di reservoir akibat sumur diproduksikan secara terus menerus, sehingga memicu respon dari aquifer. Water influx terjadi sebagai respon dari aquifer terhadap penurunan tekanan di reservoir. Salah satu respon aquifer berupa ekspansi air ke reservoir (Permadi, 2004).

Permasalahan produksi air yang meningkat menyebabkan kapasitas tangki tidak mampu menampung air yang terproduksikan. Produksi air pada lapangan A sebesar 50219 BWPD. Sedangkan kapasitas tangki penampungan hanya 25000 barel (BOB PT BSP-Pertamina hulu, 2018). Untuk menanggulangi kelebihan air, sebagian air tersebut dibuang ke sumur disposal atau diinjeksikan kembali ke dalam sumur untuk tujuan pressure maintenance atau improved oil recovery (Komar Tiskana dan Supriyadi, 1994). Untuk menginjeksikan air ke sumur injeksi diperlukan tenaga pendorong yang besar berasal dari pompa. Pada lapangan A terdapat dua jenis pompa injeksi yaitu Water Injection Plant(WIP) dan Electrical Submersible Pump (ESP). Jumlah air yang diinjeksikan menggunakan pompa WIP sebesar 40719 BWPD dan menggunakan pompa ESP sebesar 9500 BWPD (BOB PT BSPPertamina hulu, 2018).

Supaya penginjeksian berjalan maksimal dilakukan perhitungan kapasitas pompa yang sesuai dengan laju alir yang diinginkan. Dalam menginjeksikan air menuju sumur injeksi diperlukan rancangan atau singkronisasi mulai dari tangki penampungan, sumur disposal dan kapasitas pompa. Hal ini bertujuan supaya proses penginjeksian berjalan 
lancar dan sesuai dengan target injeksi yang direncanakan.Tujuan dari penelitian ini adalah :

1. Menghitung besarnya volume air ditangki penampungan,dan volume sumur disposal lapangan A.

2. Mengevaluasi pompa Electrical Submersible Pump (ESP) sebagai pompa injeksi air pada sumur disposal lapangan $\mathrm{A}$

Berdasarkan latar belakang dan tujuan penelitian ini, rumusan masalah dalam penelitian ini, di fokuskan pada perhitungan volume ditangki penampungan, volume sumur disposal dan menghitung kapasitas pompa terpasang yang akan dilakukan sinkronisasi.

Manfaat dari penelitian adalah :

1. Dapat mengatasi permasalahan air terproduksi dilapangan minyak BOB PT BSP- Pertamina Hulu,

2. Menambah kridit point bagi Peneliti, ProgramStudi, Fakultas Teknik danUniversitas.

\section{METODE PENELITIAN}

Penelitian ini berlangsung selama 6 (enam) bulan, yang dilaksanakan pada bulan 14 Desember 2020 sampai dengan 30 Juli 2021. di Lapangan Minyak BOB PT.BSP- Pertamina Hulu.

\section{Teknik Analisis Data}

Teknik analisis data adalah mengambil beberapa data sumur sebagai sumur kajian. Pengambilan data sumur kajian berdasarkan konsultasi dari coordinator lapangan di bidang produksi dari data tersebut dihitung volume tangki, dihitung laju alir ke sumur disposal dan ter akhir ditung kapasitas pompa yang digunakan. Semua parameter ini harus disingkron kan supaya injeksi air ke reservoir dapat berjalan dengan lancar. Dan air terproduksi tidak bermasaalah.

\section{Analisis Pengolahan Data}

Didalam melakukan analisis data persamaan atau rumur yang digunakan adalaha sebagai berikut :

1. Persamaan Untuk Menghitung Volume tangki Penampungan

$$
\rho 1 . A 1 . v 1=\rho 2 . A 2 . v 2^{12)}
$$

Fluida incompresible $\rho 1=\rho 2$

$A 1 . v 1=A 2 . v 2^{16)}$

Dimana :

$\rho=$ Massa jenis fluida $(\mathrm{gr} / \mathrm{cc})$

$\mathrm{A}=$ Luas penampan galiran (m2)

$\mathrm{v}=$ Kecepatanaliran $(\mathrm{m} / \mathrm{s})$

Menentukan ketinggian air pada tanki menggunakan persamaan hukum Bernoulli (Brown, K.E. 1984)

$$
\begin{aligned}
& \left(\frac{\mathrm{P} 1}{\rho g}+\frac{\mathrm{v}_{1}^{2}}{2 \mathrm{~g}}+\mathrm{Z} 1\right)=\left(\frac{P 2}{\rho g}+\right. \\
& \left.\left.\frac{v_{2}^{2}}{2 g}+Z_{2}\right)+\mathrm{HL}^{12}\right)
\end{aligned}
$$

Dimana :

$$
\mathrm{Z} \quad=\text { Ketinggian }(\mathrm{m})
$$

$\mathrm{H}_{\mathrm{L}} \quad=$ Head Loss dari titik satu ketitikdua

$$
\begin{aligned}
& R e=92,1 \frac{\left.\left(S G_{w}\right) Q_{1} 10\right)}{d \mu} \\
& H l=f \frac{L}{D} \frac{V^{2}}{2}+K \frac{V^{2}}{2}
\end{aligned}
$$

Dimana $\mathrm{P}_{1}=\mathrm{P}_{2}=\mathrm{P}_{\mathrm{atm}}, v_{1}=0$, dan $\mathrm{z}_{2}=$ 0

$$
\begin{aligned}
& z_{1}-\frac{v_{2}^{2}}{2 g}=f \frac{L}{D} \frac{V^{2}}{2}+K \frac{V^{2}}{2} \\
& z_{1}=f \frac{L}{D} \frac{V^{2}}{2}+K \frac{V^{2}}{2}+\frac{v_{2}^{2}}{2 g}
\end{aligned}
$$




$$
\begin{gathered}
z_{1}=\frac{1}{g} \times \frac{v^{2}}{2}\left\{f \frac{L}{D}\right. \\
v=\frac{Q}{A}=\frac{4 Q}{\pi D^{2}} \\
z_{1}=\frac{8 Q_{\text {pipe }}{ }^{2}}{\pi^{2} D_{\text {pipe }}{ }^{4} g}\left[f \frac{L}{D_{\text {pipe }}}+K+\right. \\
1]
\end{gathered}
$$

$V_{\text {annulus }}$

$=V_{\text {casing pertama }}$

- V casing kedua

e. Luas penampang annulus

$A_{\text {annulus }}=\frac{\pi}{4} D^{2}$

KecepatanAlir Annulus

$v_{2}=\frac{v_{1} A_{1}}{A_{2}}$

f. Laju Alir Pada

Annulus

$\mathrm{Q}=\mathrm{v} \times \mathrm{A}$

$V_{-}$(sumur penampungan)

$=V_{-}($annulus pertama $)$

$+V_{-}$(annulus kedua)

$V_{\text {annulus kedua }}$

$=V_{\text {casing kedua }}-V_{\text {tubing }}$

$V_{\text {tubing }}=\pi x r^{2} \times h$

Besarnya laju alir di anulus

$Q=v \times A \operatorname{dan} Q$

$$
=2,63 \frac{f t}{s} \times 0,2342 f t^{2}
$$

3. Perhitungan Pompa ESP

Working fluid level

Head friction

$$
W f l=h-P w f / G f
$$

$$
H f=f x h
$$

Total Dinamic Head (TDH)

$$
T D H=W f l+\frac{p w h}{G f}+H f
$$

Kecepatan disubstitusikan

dapat Volume tangki dengan ketinggian $\mathrm{z}$ dapat dihitung dengan menggunakan persamaan :

$$
\mathrm{V}=\pi \times \mathrm{r}^{2} \times \mathrm{Z}_{1}
$$

2. Perhitungan Volume Sumur Disposal

a. Volume casing

b. $\quad V_{1}=\pi x r^{2} \times h$

c. Volume annulus

d. Diameter annulus

$V_{\text {annulus }}=\pi x r^{2} \times h$

Head Capacity dan Horse Powerdiperolehdaripembacaankurva Pump Performance Curve

Stages: stages $=\frac{T D H}{H c}$ dan $\mathrm{HHP}$

Hp motor $x$ stage

\section{HASIL DAN PEMBAHASAN}

Permasalahan yang terjadi pada saatini di lapangan A yaitu fasilitas tangki air (water tank )tidak mampu untuk menampung jumlah air yang terproduksikan. Jumlah air terproduksi pada lapangan A sebesar 50219 BWPD. Sedangkan kapasitas tangki air (water tank) pada gathering station lapangan A hanya 25000 barel. Untuk menanggulangi kelebihan air, maka diperlukan sumur penampungan (sumur disposal). Dari sumur disposal ini dilakukan penginjeksian airke reservoir.Untuk penginjeksian air ke reservoir diperlukan tekanan yang besar yang berasal dari pompa. Pompa yang digunakan pada lapangan A yaitu Electrical Submersible Pump(ESP). 


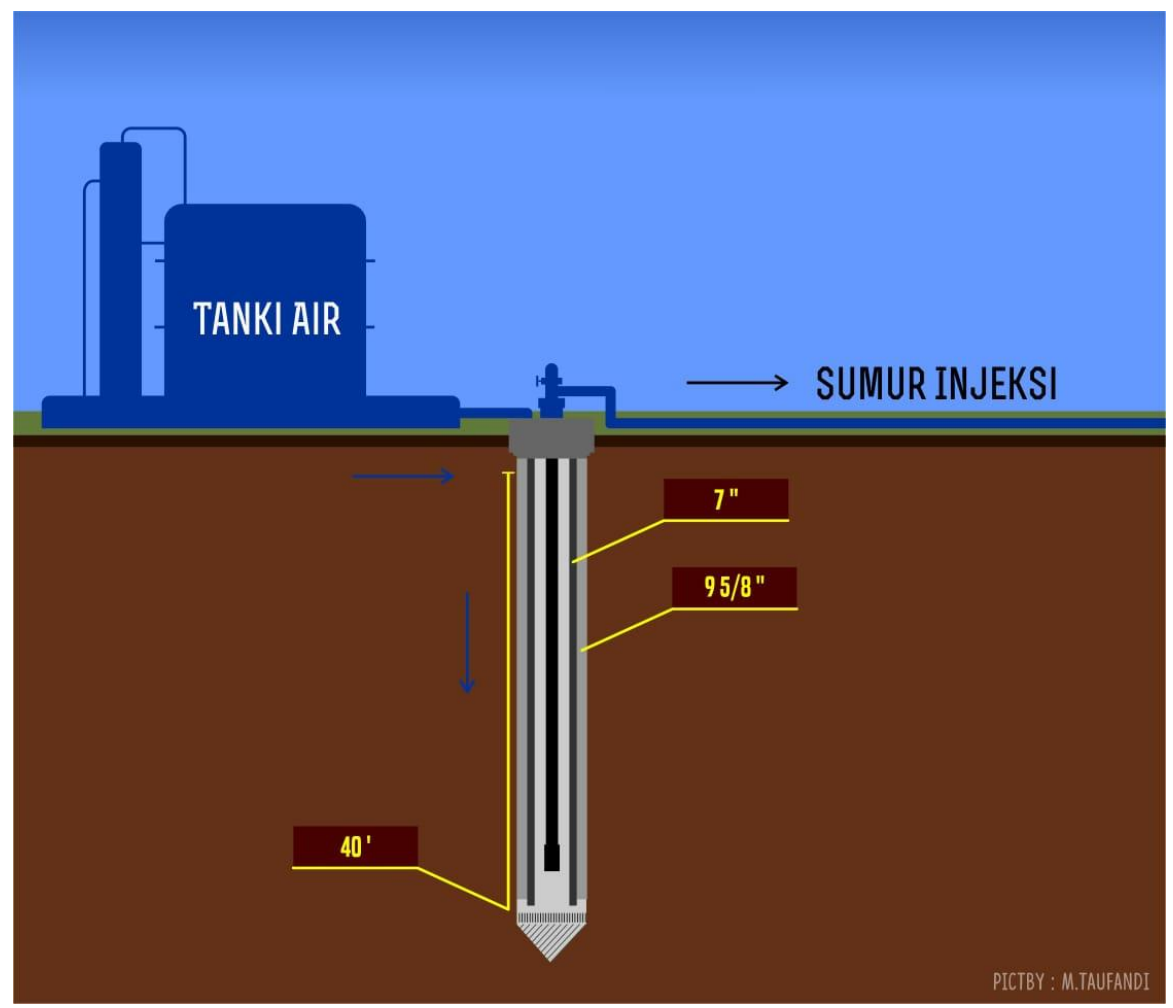

Gambar 1. Sumur disposal

Tangki Air Penampungan Dan Sumur Disposal

Dari tangki penampungan air dialirkan menuju sumur disposal. Pada sumur disposal ini pompa Electrical Submersible Pump (ESP) bekerja sebagai pompa injeksi, untuk menginjeksikan air ke sumur injeksi, langkah pertama yang harus dilakukan yaitu mengalirkan air menujusumurpenampungan. Jumlah air yang akan diinjeksikan pada sumur 01 dan 02 sebesar 9500 BWPD. Jumlah ini harus sama banyak dengan air yang keluar dari tangki menuju sumur Disposal

Untuk mendapatkan laju alir sebesar 9500 BWPD, terlebih dahulu ditentukan ketinggian air pada tangki. Hal ini dilakukan untuk mengontrol laju alir air dari tangki menuju sumur penampungan. Penentuan ketinggian air pada tanki menggunakan persamaan Bernoulli, hasil perhitungan dapat dilihat pada tabel hasil perhitungan ketinggian air pada tengki penempungan.

Tabel 1. Hasil PerhitunganKetinggian Air Pada Tangki

\begin{tabular}{cccccccc}
\hline No & $\mathbf{z}$ (ft) & D pipa (ft) & L pipa (ft) & $\mathbf{g}(\mathbf{f t} / \mathbf{s})$ & $\mathbf{f}$ & $\mathbf{Q}\left(\mathbf{f t}^{3} \mathbf{s}\right)$ & $\mathbf{Q}(\mathbf{B W P D})$ \\
\hline $\mathbf{1}$ & 4 & 0,5 & 150 & 32,2 & 0,0838 & 0,6102 & 9390,4 \\
$\mathbf{2}$ & 4,11 & 0,5 & 150 & 32,2 & 0,0838 & 0,6170 & 9500 \\
$\mathbf{3}$ & 4,2 & 0,5 & 150 & 32,2 & 0,0838 & 0,6252 & 9622,01 \\
$\mathbf{4}$ & 4,3 & 0,5 & 150 & 32,2 & 0,0838 & 0,6324 & 9732,12 \\
$\mathbf{5}$ & 4,4 & 0,5 & 150 & 32,2 & 0,0838 & 0,6400 & 9848,216 \\
\hline
\end{tabular}


Hasil perhitungan ketinggian air pada tangki, untuk mendapatkan laju alir 9500 BWPD,yaitu setinggi 4,11 $\mathrm{ft}$. Ketinggian ini harus selalu diperhatikan.

Berdasarkan perhitungan jika ketinggian air pada tangki lebih besar dari 4,11 ft, maka laju alirakan menjadi besar dan volume air pada tangki akan bertambah. Sebaliknya jika ketinggian air pada tangki lebih rendah dari 4,11 ft, maka laju alir menjadi kecil dan volume air pada tangki akan berkurang. Laju alir akan mengalami perubahan jika ketinggian air pada tangkiberubah ( Hermawan dkk, 2010).

\section{LajuAlir Pada Annulus}

Hasil perhitungan laju alir pada annulus, didapatkan laju alir sebesar 9500 BWPD. Laju alir ini sama dengan laju alir pada pipa horizontal dari tanki menuju sumur penampungan dan harus singkron.

\section{Sumur Penampungan}

Setelah diketahui laju alir pada annulus, selanjutnya menentukan volume sumur penampungan. Mengetahui volume penampungan berguna untuk mengetahui kapasitas total yang mampu ditampung oleh sumur. Volume sumur dapat diketahui dengan cara pengurangan volume casing kedua dengan volume tubing. Berdasarkan perhitungan volume sumur penampungan sebesar 2,7495 barel. Laju alir yang masuk keannulus sumur sebesar 9500 BWPD.

\section{Electrical Submersible Pump (ESP)}

Pompa Electrical Submersible Pump (ESP) digunakan untuk menginjeksikan air menuju sumur injeksi..Berdasarkan laju alir fluida pada annulus sebesar 9500 BWPD, maka untuk laju alir maksimum pada pompa sama dengan laju alir fluida pada annulus. (Sujanmo. Imam W. 1995) 


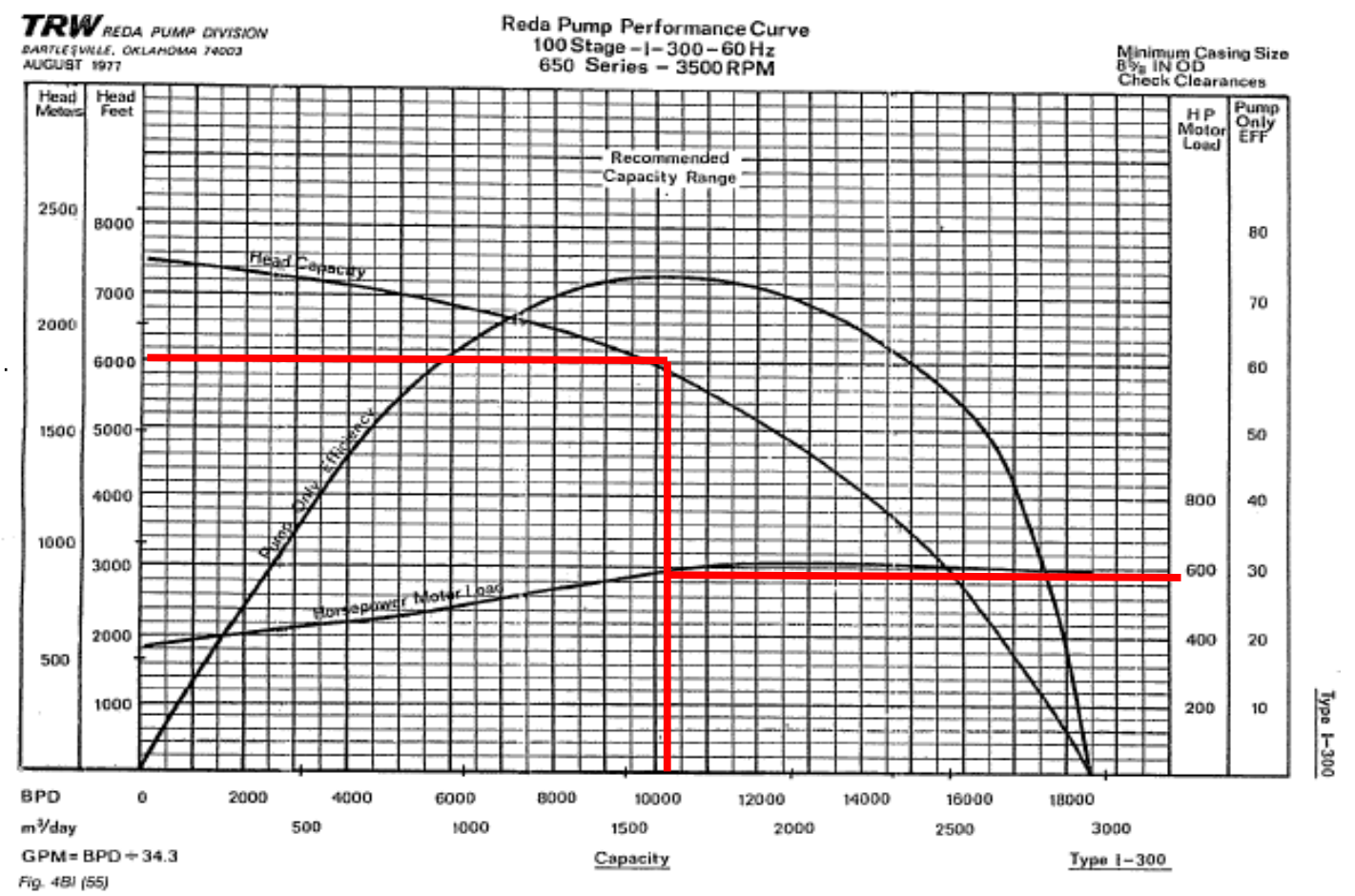

Gambar 2. Pump Performance Curve

Berdasar kanperhitungan Total Dynamic Head (TDH) pompa sejauh 1315,46 ft.Total Dynamic Head adalah jarak yang dihasilkan pompa untuk memompakan fluida dengan laju alir yang diinginkan (Brown, 1984). Berarti untuk satu kali pompadenganrate 9500 BWPD pompa mampu memompakan fluida sejauh 1315,46 ft. Selanjutnya menententukan Head capacity dan Horse Power dari grafik pump performance curve. Untuk mendapatkan target laju produksi optimal sumur yang sesuai dengan kemampuannya untuk berproduksi perlu dilakukan evaluasi pompa.Setelah diperoleh data dari grafik pump performance curve, selanjut nya menentukan jumlah stage yang dibutuhkan untuk dapat mengalirkan fluida dari dalam
sumur.Jumlah stage diperoleh berdasarkan Total Dynamic Head dan Heat Capacity yang dibutuhkan( Wilson,1986).Dari hasi lperhitungan diperoleh jumlah stage yang dibutuhkan sebanyak 22 stage. Kemudian ditentukan tenaga yang dibutuhkan untuk mendapatkan jenis motor yang digunakan pada pompa. Hasil perhitungan diperoleh tenaga yang dibutuhkan sebesar 129,8 Hp dan jenis motor yang digunakan berdasarkan tabel motor pada lampiran yaitu $130 \mathrm{Hp}, 635$ volt, dan 95 ampere.

Berdasarkan perhitungan secara manual, maka didapatkan jenis pompa yang sesuaiyaitu Reda I 30060Hz-650 series- 3500 RPM yang memiliki kemampuan produksi 8000 11000 BPD. Untuk laju alir sebesar 9500 BWPD pompa ini 
membutuhkan 22 stage. Tekanan pada kepala sumur sebesar 560 psig yang digunakan sebagai tekanan injeksi untuk dua sumur injeksi.

Dari pompa yang terpasang dilapangan tidak memenuhi kapasitas yang dinginkan sebesar 9500 BWPD dan hanya 9135 BWPD untuk pompa harus di size up sesuai dengan pompa hasil perhitungan.

Tabel 2 Hasil DesainPompa ESP

\begin{tabular}{ccc}
\hline No & Data Pompa & \\
\hline $\mathbf{1}$ & JenisPompa & 22 \\
$\mathbf{2}$ & Jumlahstage & 129,8 \\
$\mathbf{3}$ & $\mathrm{HHP}(\mathrm{Hp})$ & 1315,46 \\
$\mathbf{4}$ & TDH (ft) & $130 \mathrm{Hp}, 635 \mathrm{volt}, 95 \mathrm{Amper}$ \\
$\mathbf{5}$ & Jenis motor & $1 \mathrm{CU} 2 / 0 \mathrm{AL}$ \\
$\mathbf{6}$ & Jeniskabel & $150 \mathrm{KVA}$ \\
$\mathbf{7}$ & JenisTransformator & $120 \mathrm{MFH}, 1000$ volt, $160 \mathrm{HP}$, dan 120 ampere \\
$\mathbf{8}$ & JenisSwitchboard &
\end{tabular}

\section{KESIMPULAN}

Berikut kesimpulan yang didapat dari penelitian ini :

1. Ketinggian air pada tangki penampungan untuk mempertahankan laju alir sebesar 9500 BWPD adalah 4,11 ft dengan volume 256,88 barel. Sedangkan Untuk laju alir pada annulus antara casing pertama dan kedua adalah sebesar 9500 BWPD.

2. Hasil perhitungan kapasitas pompa ESP 9500 BWPD yaitu menggunakan jenis pompa Reda I 300-60Hz-650 series dengan perhitungan stage yang dibutuhkan 22 stage.

\section{DAFTAR PUSTAKA}

BOB PT Bumi Siak Pusako Pertamina Hulu. 2007. Sejarah Lapangan dan LetakGeografis. BOB PT BumiSiakPusako Pertamina Hulu, 2018. EOR
Operation Report and Operation File, CPP area.

Brown, K.E. 1984. The Technology of artificial Lift Methods (Volume 2b). USA: The University of Tulsa.

Jaya, P., Rahman, A. dan Herlina, W. 2014. Evaluasi

Pompa Electric Submersible Pump (ESP) untuk Optimasi Produksi pada Sumur P-028 Dan P-029 di PT. Pertamina EP Asset 2 Pendopo Field. Teknik PertambanganUnsri.

Hermawan, Y.D. Suksmono, Y., Dewi, D.U. dan Widyaswara, W. 2010. Dinamika Level Cairan Pada SistemTangki Seri Tak Berinteraksi dengan Arus Recycle. Prosiding Seminar Nasional Teknik Kimia Kejuangan.

Kumar, S. 2013. Design of An Electrical Submersible Pump. Paper International Journal of Scientific \& Engineering Research. Volume 4 
Manajemen Produksi Hulu Pertamina. 2003. Pertamina. Perencanaan dan Troubleshooting pada Pompa ESP.

Ntengwe, F.W., Chickwa, M. dan Witika, L.K. 2015. Evaluation Of Friction Losses In Pipe and Fittings Of Process Engineering Plants. Interational Journal Of Scientific and Technology Research Volume 4.

Permadi, A.K. 2004. Diktat Teknik Reservoir II. InstitutTeknologi Bandung: Bandung

Sefilra, A. 2012. Evaluasi Dan Desain Ulang Electrical Submercible Pump Pada Sumur $X$ Lapangan $Y$. Teknik GEOLOGI UPN. Yogyakarta.

Sujanmo. I.W. 1995. Electrical Submersible Pump. Pabelokan.

Tiskana, K. dan Supriyadi. 1994. Injeksi Air Ditinjau dari Upaya
Pelestarian Lingkungan.

Simposium dan Kongres IATMI.

Riestyastuti, W. 2012.

EvaluasiPompa Electric

Submersibel (ESP)

SumurKwgWk Di

LapanganKawengan Area Cepu PT. Pertamina EP Region Jawa.TeknikGeologiUPN.Yogy akarta.

Williansom, J. dkk. 1998. First North Slope Installed Water Injection Booster using Below Grade Electrical Submersible Pump $(E S P)$, Society Of Petroleum Engineering.

Wilson, B.L. dan Oil Dynamics Inc. 1986. Understanding The Basics Of Electrical Submersible Pump Performance. Society Of Petroleum Engineering. 